\title{
KOMUNIKASI ORGANISASI, SUPERVISI, DAN LINGKUNGAN KERJA MENINGKATKAN KEPUASAN KERJA PEGAWAI DINAS PENDIDIKAN DAN KEBUDAYAAN SUBANG
}

\author{
Rika Rahmawati ${ }^{1}$, Didin Saepudin ${ }^{2}$, Taufik Zulfikar ${ }^{3}$ \\ ${ }_{1,2,3}$ Universitas Sangga Buana \\ ${ }^{1}$ korespondensi : kakangkarina@gmail.com
}

\begin{abstract}
Every organization, whether profit-oriented or not, will have goals or objectives to be achieved. These goals or objectives will be achieved if employees or people in the organization have good performance. Good employee performance will be obtained when employees or people in the organization have job satisfaction. This research aims to determine and analyze the effect of organizational communication, supervision, and work enviroment on job satisfaction with the object of research employees at the Education and Culture Office of Subang Regency. The research method used is quantitative with a descriptive verification approach, multiple linear regression is used as an analysis tool with 90 employees as respondents. The survey method carried out is by giving a questionnaire to the questionnaire as many as 25 questions with closed answers. The results showed that the supervised variable was perceived as the best variable with a value of 4.22 and the work environment variable became the worst variable with a value of 3.85. Organizational communication, supervision, and work environment variables have a positive and significant influence on job satisfaction either partially or simultaneously.
\end{abstract}

Keywords: Organizational communication, Supervision, Work environment, Job satisfaction

\begin{abstract}
ABSTRAK
Setiap organisasi baik yang berorientasi laba ataupun tidak akan mempunyai tujuan atau sasaran yang akan dicapai. Tujuan atau sasaran tersebut akan tercapai apabila pegawai atau orang-orang yang ada dalam organisasi tersebut mempunyai kinerja yang baik. Kinerja pegawai yang baik akan diperoleh manakala peawai atau orang-orang dalam organisasi tersebut memiliki kepuasan kerja. Tujuan dari penelitian ini untuk menganalisa dan mengkaji pengaruh dari komunikasi organisasi, supervise, dan lingkungan kerja terhadap kepuasan kerja dengan objek penelitian pegawai pada Pendidikan dan Kebudayaan Kabupaten Subang. Metode penelitian yang digunakan adalah kuantitatif dengan pendekatan deskriptif verifikatif, regresi linear berganda digunakan sebagai alat analisa dengan responden sebanyak 90 orang pegawai. Metode survei yang dilakukan adalh dengan memberikan kuesioner terhadap kuesioner sebanyak 25 pertanyaan dengan jawaban tertutup. Hasil penelitian menunjukan bahwa variabel supervise dipersepsikan sebagai variabel terbaik dengan nilai 4,22 dan variabel lingkungan kerja menjadi variabel terjelek dengan nilai 3,85. Variabel komunikasi organisasi, supervisI, serta lingkungan kerja mempunyai pengaruh positif dan signifikan terhadap kepuasan kerja pegawai baik secara partial maupun simultan.
\end{abstract}

Kata Kunci : Komunikasi organisasi, Supervisi, Lingkungan kerja, Kepuasan kerja

\section{PENDAHULUAN}

Diamanatkan dalam UU RI Nomor. 20 Tahun 2003 tentang Sistem Pendidikan Nasional dimana fungsi pendidikan dengan tujuan untuk berkembangnya potensi peserta didik dengan mengembangkan kemampuan, membentuk karakter, dan peradaban bangsa yang bermartabat dalam rangka mencerdasakan kehidupan bangsa agar menjadi manusia yang beriman dan bertakwa kepada Tuhan Yang Maha Esa, berakh;ak mulia, sehat, cakap, kreatif, berilmu, mandiri, dan menjadi warga negara yang demokratis serta bertanggung jawab. Fungsi itu dapat terwujud apabila ada peran serta stakeholder yaitu pemerintah, masyarakat, orang tua, peserta didik, guru, tenaga kependidikan. Dinas Pendidikan dan Kebudayaan 
Kabupaten Subang berfungsi diantaranya sebagai a) pembinaan dan pelaksanaan tugas dibidang pendidikan usia dini dan pendidikan non formal, pendidikan dasar SD/SMP serta kebuadayaan. b) penyelenggara urusan pemerintah dan pelayanan umu dibidang pendidikan usia dini, dan pendidikan non formal, pendidikan dasar SD/SMP serta kebudayaan. c) penyelenggraan pembinaan, pengelolaan Unit Pelaksana Tekhnis (UPT) dinas. Dinas Pendidikan dan Kebudayaan Kabupaten Subang mengelola sebanyak 1.390 sekolah pada semua jenjang pendidikan dengan jumlah murid sebanyak 213.704 orang dan guru sebanyak 11.633 orang. Supaya fungsi penyelenggaran, pelayanan umum, pembinaan dan pengawasan dibidang pendidikan berjalan dengan baik maka dalam pengeloaannya diperlukan pegawai dinas Pendidikan dan Kebudayaan Kabupaten Subang yang memiliki kinerja baik.

Pegawai dengan kinerja baik dapat dipengaruhi oleh kepuasan kerja pegawai. Produktivitas dan kinerja baik pegawai maupun organisasi dapat ditingkatkan dengan suskses berkat organisasi yang efisien dan efektif.. Maka dari itu bagi organisasi penting untuk memperhatikan faktor-faktor yang mempengaruhi produktifitas dan kinerja pegawai, dan salah satunya yang penting adalah kepuasan kerja pegawai. Pegawai yang memiliki tingkat kepuasan kerja yang tinggi cenderung lebih memberikan kontribusi, berkomitmen dan mempunyai dedikasi yang tinggi terhadap organisasi dan akhirnya mempunyai kemauan untuk bekerja lebih keras dan lebig produktif. Sebaliknya , pegawai yang memiliki tingkat kepuasan kerja yang rendah cenderung akan melakukan berhenti bekerja, atau menurunya disiplin dan produktivitas kerja. Terciptanya kepuasan kerja pegawai maka salah satunya diperlukan komunikasi organisasi yang berjalan baik. Komunikasi organisasi di dalam perusahaan dapat diciptakan dengan baik apabila terjadi kesepahaman antara pengirim dan penerima. Karena sudah dibekali oleh informasi yang jelas dan akurat serta efektifnya komunikasi, para pegawai dapat bekerja dengan baik maka akan muncul kepuasan kerja atas hasil yang dikerjakannya [1]. Suatu organisasi dapat diuntungkan apabila saluran komuniaksi organisasi formal dan informal berjalan dengan baik. Organisasi dituntut untuk mencapai tujuan bersama, sehingga memerlukan adanya suatu penerimaan dan pemaknaan pesan yang efektif. Saluran komunikasi yang baik dimiliki oleh Organisasi akan membuat pegawai bekerja dengan nyaman dan kondusif [2].

Supervisi dari atasan juga dapat membatu pegawai dalam mencapai kepuasan kerja. Peran supervisi dalam organisasi sangat besar, karena seorang supervisor memerlukan kemampuan dalam mengendalikan ancaman yang bisa menghambat kelancaran jalannya organisasi yang memiliki pengaruh besar terhadap kinerja perusahaan [3]. Malalui peningkatan kompetensi profesionalitas, supervise dan disiplin kerja peningkatan kinerja guru perlu dipertimbangkan yang berpihak pada kesejahteraan guru, terbuka dan menekankan pada prestasi, karena tugas guru terkait dan dibuktikan dengan keberhasilan 
pendidikan siswa [4]. Pengawasan atau supervise perlu dilakukan pemimpin untuk mengarahkan pegawai agar dapat melakukan pekerjaan dengan tepat pada setiap aktivitas yang dilakukan oleh organisasi [5].

Kepuasan kerja pegawai juga dapat dipengaruhi oleh keadaan lingkungan kerja, baik lingkungan kerja fisik maupun lingkungan kerja non fisik. Beberapa penelitian yang telah dilakukan menunjukkan hal tersebut [6]; [7];[8]; [9].

Berdasarkan hal tersebut di atas maka tujuan dari penelitian ini adalah untuk menganalisa dan mengkaji pengaruh komunikasi organisasi, dan lingkungan kerja terhadap kepuasan kerja.

\section{TINJAUAN PUSTAKA}

\section{Komunikasi Organisasi}

Menurut Katz dan Kahn komunikasi organisasi merupakan arus informasi, pertukaran informasi dan pemindahan arti di dalam suatu organisasi [1]. Clampitt mengatakan arti komunikasi organisasi merupakan suatu proses mengirimkan dan menerima informasi/pesan dan pemindahan arti dalam kelompok formal ataupun informal pada suatu organisasi [10]. Komunikasi organisasi adalah suatu proses penyampaian dan penerimaan pesan di suatu organisasi dari segala arah untuk menciptakan tujuan organisasi tersebut [11]. Pengertian komunikasi organisasi maka dapat disimpulkan suatu proses penyampaian dan penerimaan informasi yang bersifat formal dan informal dalam suatu organisasi. Menurut Goldhaber terdapat 7 (tujuh) konsep yang terkandung di dalamnya : a. Proses (process), suatu organisasi adalah suatu sistem terbuka dan dinamis yang saling menciptakan dan saling menukar pesan diantara anggotanya. Karena gejala menciptakan dan menukar ini terus berjalan terus menerus dan tidak ada henti hentinya, maka dikatakan sebagai suatu proses. b. Pesan (message), adalah susunan simbol yang penuh arti tentang segala sesuatu entah itu orang, objek, dan kejadian yang dihasilkan oleh interaksi orang lain untuk berkomunikasi. c. Jaringan (network), dalam suatu organisasi terdapat orang-orang yang menempati posisi atau peranan tertentu dalam organisasi. d. Keadaan saling membutuhkan (interdependence), konsep kunci dalam komunikasi organisasi lainnya adalah keadaan saling membutuhkan satu dengan lainnya. e. Hubungan (Relationship), organisasi merupakan sistem terbuka, sistem kehidupan sosial, maka untuk berfungsinya sistem tersebut terletak pada manusianya. Oleh sebab itu hubungan manusia dengan organisasi sangat penting. f. Lingkungan (environment) lingkungan adalah semua totalitas secara fisik dan faktor sosial diperhtungkan dalam pembuatan keputusan mengenai individu dalam suatu sistem. g. Ketidakpastian (Uncertainly) adalah perbedaan informasi yang diharapkan dengan informasi yang tersedia [12].

\section{Supervisi}

Supervisi didefinisikan sebagai pembianaan dan pengawasan yang dilakukan pimpinan terhadap seluruh komponen untuk mencapai tujuan yang diinginkan dengan ukuran : 
Jumlah kunjungan yang dilaksanakan, pembahasan hasil kunjungan, pembimbingan pelaksanaan tugas, pemecahan masalah melakukan pengawasan, memotivasi, menjalin kerja sama dan melakukan evaluasi. [13]. Supervisi merupakan suatu kegiatan yang dilakukan oleh supervisor untuk memberikan bantuan professional terhadap guru dalam menjalankan pekerjaannya yang menjadi tanggung jawabnya dengan ukuran a) perbaikan dan tindak lanjut, b) frekuensi observasi, c) kesesuaian evaluasi terhadap hasil supervise, dan d) intensitas pembinaan [14]. Supervisi suatu proses mengarahkan, mendukung staf agar dapat mengerjakan tugasnya secara efektif. Supervisor harus menggunakan kesempatan, terutama untuk mendengar dan memberi perspektif serta klarifikasi praktek dengan teori [5]. Supervisi yang efektif dengan cicir-ciri sebagai berikut; a. Delegasi. dengan waktu dan tenaga yang terbatas mengakibatkan supervisor mendelegasikan sebagian tugas-tugasnya. b, Keseimbangan, supervisor harus menjaga keseimbangan tugasnya untuk mengambil keputusan dan memberikan tugas sebagai wujud sikap tegas dan pemberian kesempatan kepada bawahannya untuk berkembang. c. Penghubung, supervisor adalah penghubung antara staf dengan manajemen puncak sehingga harus dapat menyampaikan keinginan dan atau usulan/saran pada pihak manajemen d. Komunikasi, agar terdapat kemudahan dalam berkomunikasi supervisor hendaknya mempergunakan bahasa yang mudah dipahami oleh semua pihak [5].

\section{Lingkungan Kerja}

Lingkungan kerja merupakan aspek yang sangat penting bagi kelangsungan suatu pekerjaan. Menurut Sedarmayanti yang dimaksud dengan lingkungan kerja adalah keseluruhan alat kerja dan bahan yang dihadapi, lingkungan sekitarnya dimana seseorang bekerja, metode kerjanya, serta pengaturan kerjanya baik sebagai kelompok maupun perorangan. Pendapat Nitisemito lingkungan kerja sebagai sumber inforamsi dan tempat beraktifitas, sehingga lingkungan kerja yang baik terjadi agar pegawai merasa lebih dan nyaman di dalam tempat kerja untuk menyelesaikan pekerjaannya menyebabkan tingkat efisiensi dapat tercapai [6]. Definisi lingkungan kerja menurut Sutrisno yaitu semua sarana dan peralatan kerja yang ada di sekitar pegawai melakukan pekerjaan yang akan dapat mempengaruhi pekerjaan yang sedang dilakukan. Lingkungan kerja meliputi tempat kerja, fasilitas dan alat bantu pekerjaan, kebersihan, penerangan, ketenangan, dan hubungan kerja antar orangorang di tempat kerja tersebut [8]. Lingkungan kerja pada dasarnya merupakan terkait dengan komponen atau berbagai macam faktor yang ada di sekitar pegawai yang dapat berpengaruh secara langsung ataupun tidak langsung terhadap kinerja [9]. Menurut pendapat para ahli di atas maka lingkungan kerja dapat disimpulkan tempat atau lingkungan dimana sumber daya manusia dapat bekerja baik secara perorangan maupun kelompok untuk menyelesaikan pekerjaannya [6]. Secara garis besar lingkungan kerja dikelompokan menjadi dua yaitu lingkungan 
kerja fisik dan lingkungan kerja non fisik [8]. Lingkungan kerja fisik adalah semua komponen atau keadaan yang ada di sekitar tempat kerja yang dapat mempengaruhi pegawai secara langsung ataupun tidak langsung kepada kinerja [6]. Menurut Nitisemito Lingkungan kerja fisik adalah segala seseuatu yang ada di sekitar pegawai yang dapat mempengaruhi pegawai dalam melaksanakan tugas-tugas yang dibebankan [6]. Sedarmayanti mendefinisikan lingkungan bukan fisik mencakup semua keadaan yang terjadi berkaitan dengan hubungan kerja, baik hubungan antara bawahan dengan atasan, maupun hubungan sesama pegawai [6]. Sedangkan menurutr Nitisemito bahwa organisasi hendaknya dapat menciptakan kondisi kerja yang mendukung kerja sama antara atasan bawahan, maupun sesama pegawai yang setingkat di organisasi [6]

\section{Kepuasan Kerja}

Definisi dari kepuasan kerja adalah mengacu pada sikap umum yang merupakan hasil dari beberapa sikap khusus terhadap faktor-faktor pekerjaan, penyesuaian diri, dan hubungan antara perorangan di luar pekerjaan [13]. Kepuasan kerja adalah sikap dan persepsi, rasa senang dan rasa tidak senang yang terjadi berdasarkan penilaiannya terhadap situasi pekerjaannya dengan ukuran perasaan terhadap a). pekerjaan itu sendiri, b) kesempatan promosi, c) aktualisasi, d) kondisi kerja, e) benefit, f) rekan kerja, dan g) pemangku kepentingan [14], Menurut Danang Sunyoto kepuasan kerja adalah suatu keadaan emosional yang menyenangkan dan tidak menyenangkan dalam hal pegawai memandangkan pekerjaannya [1], Pendapat Handoko kepuasan kerja adalah perasaan seorang pegawai terhadap pekerjaannya. Hal ini tampak dalam sikap poitif pegawai terhadap pekerjaan dan segala sesuatu yang dihadapi di lingkungan kerjanya [9]. Terdapat tiga hal penting yang harus diperhatikan dalam mempengaruhi kepuasan kerja pegawai, a) keadaan yang mendorong pegawai adalah pekerjaan yang menantang antara lain perasaan berpretasi, bertanggung jawab, kemajuan, dapat menikmati pekerjaan itu sendiri, dan adanya pengakuan atas hasil pekerjaannya. b) keadaan yang mengecewakan pegawai adalah terutama faktor yang dianggap remeh pada pekerjaan, peraturan pekerjaan, penerangan, istirahat, jabatan, hak, gaji, tunjangan dan lain sebagainya. c) Pegawai akan tidak puas apabila terbatasnya kesempatan untuk berprestasi. Pegawai akan sensitive pada lingkungannya serta mulai mencari-cari kesalahan. [8].

\section{Hubungan Komunikasi Organisasi dengan}

\section{Kepuasan Kerja}

Penelitian yang dilakukan oleh Tenang Safari (2019) dengan judul Pengaruh komunikasi organisasi terhadap kepuasan kerja karyawan di PD. BPR LPK Garut Kota Cabang Bayongbong terbit pada jurnal ilmiah MEA (Manajemen, Ekonomi, dan Akuntnasi), 3(2) 134-149 dengan mempergunakan alat analisis regresi sederhana hasil penelitian bahwa komunikasi organisasi berpengaruh positif dan signifikan terhadap kepuasan kerja. 
Penelitian yang dilakukan oleh Novieka Arik Prasetya (2018) dengan judul pengaruh komunikasi organisasi terhadap kepuasan kerja dan komitment organisasional (Studi pada karyawan PT.PLN Persero Area Pasuruan) diterbitkan oleh Jurnal Administrasi Bisnis (JAB) Vol 61, No. 4, dengan alat analisa regresi linear berganda hasil menunjukkan bahwa Kepuasan kerja dapat dipengaruhi oleh komunikasi organisasi formal dan komunikasi organisasi non formal. Penelitian yang dilakukan oleh Makarawung Seidy, Adolfina, dan Ferdi Roring (2018) dengan judul Pengaruh Komunikasi dan Kompensasi terhadap Kepuasan Kerja pad Karyawan Radio Republik Indonesia (RRI) Menado yang terbit pada jurnal EMBA, Vol.6, No. 4, dengan alat analisa linear berganda hasil menunjukkan bahwa komunikasi mempunyai pengaruh positif dan signifikan terhadap kepuasan kerja.

Hipotesis 1 : Terdapat pengaruh komunikasi organisasi terhadap kepuasan kerja

\section{Hubungan Supervisi dengan Kepuasan Kerja}

Penelitian yang dilakukan Sri Sarjana (2012) terbit pada Jurnal Kependidikan, Volume 42, Nomor 2, November 2012, Halaman 173 186 dengan judul Pengaruh Supervisi dan Iklim Organisasi terhadap Kepuasan Kerja membuktikan bahwa supervise berpengaruh positif dan signifikan terhadap kepuasaan kerja. Penelitian oleh Erlina Oktaviani dan Aan Marlinah dengan judul Pengaruh tindakan supervisi, motivasi, profesionalisme, locus of control, dan konflik peran terhadap kepuasan kerja yang terbit pada Jurnal Bisnis dan Akuntansi Vol. 16, No. 1 Tahun 2014 menemukan bahwa terdapat pengaruh yang positif dari tindakan supervise terhadap kepuasan kerja.

Hipotesis 2 : Terdapat pengaruh supervise terhadap kepuasan kerja

\section{Hubungan Lingkungan Kerja terhadap}

\section{Kepuasan Kerja}

Penelitian yang dilakukan oleh Quinerita dan Mahendra Fakhri (2015) dengan judul pengaruh lingkungan kerja terhadap kepuasan kerja karyawan lapangan Departemen Graberg Power Distribution PT. Freeport Indonesia menggunakan regresi linear berganda menunjukan hasil bahwa kepuasan kerja pegawai dapat dipengaruhi oleh lingkungan kerja fisik dan lingkungan kerja non fisik terbit pada jurnal Modus Vol 27 (2), 141-162. Penelitian yang dilakukan oleh Mukti Wibowo, Mochammad Al Musadieq, dan Gunaan Eko (2014) dengan judul peneltian Pengaruh lingkungan kerja terhadap kepuasan kerja karyawan (Studi pada karyawan PT. Telekomunikasi Indonesia Tbk, Kadantel Malang) dengan mempergunakan alat analisis regresi linear berganda menunjukan hasil bahwah lingkungan kerja fisik dan bukan fisik mempunyai pengaruh terhadap kepuasan kerja, terbit pada jurnal Jurnal Adminstrasi Bisnis (JAB) Vol 16, No. 1. Penelitian yang dilakukan oleh I Wayan Roy Sarlita Putra dan I Gusti Ayu Dewi Adnyani (2019) dengan judul Pengaruh Komunikasi, Budaya Organisasi, dan Lingkungan Kerja Fisik terhadap Kepuasan 
Kerja Karyawan Ramada Bintang Bali terbit pada jurnal E-Jurnal Manajemen, Vol. 8, No. 4; 2014-2041 menunjukkan hasil bahwa komunikasi, budaya organisasi, dan lingkungan kerja fisik berpengaruh positif dan signifikan terhadap kepuasan kerja

\section{METODE}

Metode penelitian yang digunakan metode kuantitatif dengan pendekatan deskriptif dan verifikatif. Data diperoleh dengan menyebarkan kuesioner kepada responden sebanyak 90 orang. Responden adalah pegawai Dinas Pendidikan dan Kebuyaan Kabupaten Subnag. Kuesioner terdiri dari 25 pertanyaan tertutup. Metode penentuan sample yaitu propotional stratified random. Alat analisa yang digunakan regresi linear berganda dengan persamaan sebagai berikut :

$Y_{i}=\alpha+\beta_{1} X_{1}+\beta_{2} X_{2}+\beta_{3} X_{3}$
Hipotesis 3 : Terdapat pengaruh lingkungan kerja terhadap kepuasan kerja

Hipotesis 4 : Terdapat pengaruh komunikasi organisasi, supervise, dan lingkungan kerja terhadap kepuasan kerja secara simultan.

Dimana :

$\mathrm{Y}=$ Variabel kepuasan kerja

$\mathrm{a}=$ Konstanta

$\mathrm{b}=$ Koefisien regresi

$\mathrm{X}_{1}=$ Komunikasi Organisasi

$\mathrm{X}_{2}=$ Supervisi

$\mathrm{X}_{3}=$ Lingkungan Kerja

\section{HASIL DAN PEMBAHASAN}

Data Responden

Karakteristik responden yang diteliti dikelompokan berdasarkan usia, jenis kelamin, latar belakang pendidikan, dan jabatan :

\section{Tabel 1 : Responden}

\begin{tabular}{llrr}
\hline Keterangan & Kategori & Frekuensi & Persen \\
\hline Jenis Kelamin & Pria & 55 & 61 \\
& Wanita & 35 & 39 \\
\hline Usia & $<25$ tahun & 6 & 7 \\
& $25-35$ tahun & 18 & 20 \\
& $36-45$ tahun & 61 & 68 \\
& $>45$ tahun & 5 & 5 \\
\hline Pendidikan & SMA/SMK & 15 & 17 \\
& Diploma & 10 & 11 \\
& Sarjana & 49 & 54 \\
& Pascasarjana & 16 & 18 \\
\hline Jabatan & Staf & 67 & 74 \\
& Kasie & 15 & 17 \\
& Kasubag & 3 & 4 \\
& Kabid & 5 & 5 \\
\hline & Sumber : Data primer yang diolah & &
\end{tabular}

Hasil uji validitas dan uji reliabilitas variabel

Komunikasi Organisasi, Supervisi,

Lingkungan Kerja dan Kepuasan Kerja berdasarkan keluaran IBM SPSS 20.0 yang telah direkapitulasi : 
Tabel 2 : Hasil Uji Valididas dan Reliabilitas Variabel

\begin{tabular}{|c|c|c|c|c|c|c|}
\hline Variabel & Item & $\begin{array}{c}\text { Nilai } \\
\text { Koefisien } \\
\text { Validitas }\end{array}$ & $\begin{array}{c}\text { Nilai } \\
\mathbf{r} \\
\text { Tabel } \\
\end{array}$ & Keterangan & $\begin{array}{c}\text { Nilai } \\
\text { Cronbach } \\
\text { Alpha } \\
\end{array}$ & Keputusan \\
\hline \multirow{4}{*}{ Komunikasi Organisasi } & $\mathrm{X} 11$ & 0.789 & 0.3 & Valid & \multirow{4}{*}{0,853} & \multirow{4}{*}{ Reliable } \\
\hline & $\mathrm{X} 12$ & 0.870 & 0.3 & Valid & & \\
\hline & $\mathrm{X} 13$ & 0.859 & 0.3 & Valid & & \\
\hline & X.4 & 0.813 & 0.3 & Valid & & \\
\hline \multirow{5}{*}{ Supervisi } & $\mathrm{X} 21$ & 0.882 & 0.3 & Valid & \multirow{5}{*}{0,924} & \multirow{5}{*}{ Reliable } \\
\hline & $\mathrm{X} 22$ & 0.906 & 0.3 & Valid & & \\
\hline & $\mathrm{X} 23$ & 0.863 & 0.3 & Valid & & \\
\hline & $\mathrm{X} 24$ & 0.890 & 0.3 & Valid & & \\
\hline & $\mathrm{X} 25$ & 0.841 & 0.3 & Valid & & \\
\hline \multirow{9}{*}{ Lingkungan Kerja } & $\mathrm{X} 31$ & 0.695 & 0.3 & Valid & \multirow{9}{*}{0,872} & \multirow{9}{*}{ Reliable } \\
\hline & $\mathrm{X} 32$ & 0.680 & 0.3 & Valid & & \\
\hline & $\mathrm{X} 33$ & 0.741 & 0.3 & Valid & & \\
\hline & X34 & 0.753 & 0.3 & Valid & & \\
\hline & $\mathrm{X} 35$ & 0.811 & 0.3 & Valid & & \\
\hline & $\mathrm{X} 36$ & 0.723 & 0.3 & Valid & & \\
\hline & X37 & 0.725 & 0.3 & Valid & & \\
\hline & $\mathrm{X} 3.8$ & 0.657 & 0.3 & Valid & & \\
\hline & X3.9 & 0.726 & 0.3 & Valid & & \\
\hline \multirow{7}{*}{ Kepuasan Kerja } & $\mathrm{X} 41$ & 0.805 & 0.3 & Valid & \multirow{7}{*}{0,805} & \multirow{7}{*}{ Reliable } \\
\hline & $\mathrm{X} 4.2$ & 0.735 & 0.3 & Valid & & \\
\hline & $\mathrm{X} 43$ & 0.797 & 0.3 & Valid & & \\
\hline & $\mathrm{X} 44$ & 0.714 & 0.3 & Valid & & \\
\hline & $\mathrm{X} 45$ & 0.681 & 0.3 & Valid & & \\
\hline & $\mathrm{X} 46$ & 0.528 & 0.3 & Valid & & \\
\hline & X47 & 0.606 & 0.3 & Valid & & \\
\hline
\end{tabular}

Sumber : Data primer yang diolah

\section{Gambaran persepsi responden}

Komunikasi Organisasi (X1) diukur dengan 4 pernyataan, penilaian responden terhadap Komunikasi Organisasi dengan skor rata-rata sebesar 4,04 masuk dalam kategori baik. Supervisi (X2) diukur dengan 5 pernyataan, penilaian responden terhadap Supervisi dengan skor rata-rata sebesar 4,22 masuk dalam kategori sangat baik. Lingkungan Kerja (X3) diukur dengan 9 pernyataan, penilaian responden terhadap Lingkungan kerja dengan skor rata-rata sebesar 3,85 masuk dalam kategori baik. Kepuasan Kerja diukur dengan 7 pernyataan, penilaian responden terhadap Kepuasan Kerja dengan skor rata-rata sebesar 3,90masuk dalam kategori baik.

\section{Hasil Persamaan Linear Berganda}

Diperoleh bentuk persamaan regresi linier berganda sebagai berikut :

$Y=0,666+0,129 X_{1}+0,304 X_{2}+0,383 X_{3}$ 
Dari persamaan regresi linear di atas diperoleh nilai konstanta sebesar 0,666. Artinya, jika Kepuasan Kerja Pegawai tidak dipengaruhi oleh Komunikasi Organisasi, Supervisi dan Lingkungan Kerja bernilai nol, maka besarnya rata-rata Kepuasan Kerja Pegawai akan bernilai 0,666. Tanda koefisien regresi variabel bebas menunjukan arah hubungan positif dari variabel yang bersangkutan dengan Kepuasan Kerja Pegawai. Koefisien regresi variabel $\mathrm{X}_{1}$ sebesar 0,129 mengandung arti untuk setiap pertambahan Komunikasi Organisasi sebesatr satu satuan akan menyebabkan meningkatnya Kepuasan Kerja Pegawai sebesar 0,129. Koefisien regresi variabel $\mathrm{X}_{2}$ sebesar 0,304 mengandung arti untuk setiap pertambahan Supervisi sebesar satu satuan akan menyebabkan meningkatnya Kepuasan Kerja Pegawai sebesar 0,304. Koefisien regresi variabel $X_{3}$ sebesar 0,383 mengandung arti untuk setiap pertambahan Lingkungan Kerja sebesar satu satuan akan menyebabkan meningkatnya Kepuasan Kerja Pegawai sebesar 0,383.

\section{Uji t}

Untuk mengetahui signifikan atau tidaknya suatu pengaruh dari variabel-variabel bebas secara parsial atas suatu variabel tidak bebas digunakan uji t.

Tabel 3 : Hasil Uji t

\section{Coefficients $^{a}$}

\begin{tabular}{|c|c|c|c|c|c|c|}
\hline \multirow[b]{2}{*}{ Model } & & \multicolumn{2}{|c|}{$\begin{array}{l}\text { Unstandardized } \\
\text { Coefficients }\end{array}$} & \multirow{2}{*}{$\begin{array}{c}\text { Standardized } \\
\text { Coefficients } \\
\text { Beta }\end{array}$} & \multirow[b]{2}{*}{$\mathrm{t}$} & \multirow[b]{2}{*}{ Sig. } \\
\hline & & $\mathrm{B}$ & Std. Error & & & \\
\hline \multirow[t]{4}{*}{1} & (Constant) & .666 & .225 & & 2.966 & .004 \\
\hline & Komunikasi organisasi & .129 & .063 & .158 & 2.070 & .041 \\
\hline & Supervisi & .304 & .060 & .392 & 5.074 & .000 \\
\hline & Lingkungan kerja & .383 & .073 & .421 & 5.269 & .000 \\
\hline
\end{tabular}

a. Dependent Variable: Kepuasan kerja pegawai Sumber : Hasil Pengolahan Data Primer, 2021

Berdasarkan tabel 3 di atas dapat dilihat bahwa Variabel Komunikasi Organisasi $\left(\mathrm{X}_{1}\right)$ memiliki nilai sig lebih kecil dari 0,05. Karena nilai sig $(0,041)<0,05$, maka Ho ditolak. Oleh karena itu dapat disimpulkan bahwa secara parsial terdapat pengaruh signifikan dari Komunikasi Organisasi terhadap Kepuasan Kerja Pegawai. Variabel Supervisi $\left(\mathrm{X}_{2}\right)$ memiliki nilai sig lebih kecil dari 0,05. Karena nilai sig $(0,000)<0,05$, maka Ho ditolak. Oleh karena itu dapat disimpulkan bahwa secara parsial terdapat pengaruh signifikan dari Supervisi terhadap Kepuasan Kerja Pegawai. Variabel Lingkungan Kerja $\left(\mathrm{X}_{3}\right)$ memiliki nilai sig lebih kecil dari 0,05 . Karena nilai sig $(0,000)<0,05$, maka Ho ditolak. Oleh karena itu kesimpulannya adalah secara parsial terdapat pengaruh yang signifikan dari Lingkungan Kerja terhadap Kepuasan Kerja Pegawai. 
Uji F

Tabel 4 : Pengujian Hipotesis Secara Simultan (Uji F)

ANOVA $^{\mathrm{a}}$

\begin{tabular}{ll|r|r|r|r|r} 
Model & Sum of Squares & df & Mean Square & F & Sig. \\
\hline 1 & 20.926 & 3 & 6.975 & 51.298 & $.000^{\mathrm{b}}$ \\
\cline { 2 - 7 } & Regression & 11.694 & 86 & .136 & & \\
\hline & Residual & 32.621 & 89 & & & \\
\hline
\end{tabular}

a. Dependent Variable: Kepuasan kerja pegawai

b. Predictors: (Constant), Lingkungan kerja , Komunikasi organisasi, Supervisi Sumber : Data primer yang diolah

Tabel 4 di atas menunjukan nilai $\mathrm{F}$ hitung sebesar 51,298. Karena nilai F hitung $(51,298)$ $>\mathrm{F}$ tabel $(2,711)$, maka Ho ditolak. Dengan demikian dapat disimpulkan bahwa secara simultan terdapat pengaruh yang signifikan dari Komunikasi Organisasi, Supervisi dan Lingkungan Kerja terhadap Kepuasan Kerja Pegawai.

\section{Koefisien Determinasi}

Besarnya pengaruh Komunikasi Organisasi, Supervisi dan Lingkungan Kerja terhadap Kepuasan Kerja Pegawai dapat ditunjukkan oleh koefisien determinasi dengan rumus sebagai berikut:

$$
\begin{aligned}
\mathrm{KD} & =\mathrm{R}^{2} \times 100 \% \\
& =(0,801)^{2} \times 100 \% \\
& =64,2 \%
\end{aligned}
$$

Artinya variabel Komunikasi Organisasi, Supervisi dan Lingkungan Kerja memberikan pengaruh sebesar $64,2 \%$ terhadap Kepuasan Kerja Pegawai. Sedangkan sisanya sebesar $35,8 \%$ merupakan kontribusi dari variabel lain selain Komunikasi Organisasi, Supervisi dan Lingkungan Kerja.

\section{Pembahasan}

\section{Pengaruh Komunikasi Organisasi} Terhadap Kepuasan Kerja.

Hasil perhitungan yang telah dikemukakan di atas maka diketahui bahwa komunikasi organisasi berpengaruh terhadap kepuasan kerja pegawai. Hasil yang didapatkan diperoleh dari perhitungan sig 0,041 lebih kecil dari 0,05 dan nilai $t_{\text {hitung }}$ lebih besar dari $t_{\text {tabel }}(2.070>1.98472)$. Koefisien regresi komunikasi organisasi memiliki tanda positif yang berarti semakin baik komunikasi organisasi maka semakin baik juga kepuasan kerja pegawai. Hal ini sesuai dengan penelitian sebelumnya yang dilakukan bahwa komunikasi organisasi berpengaruh secara signifikan dan positif terhadap kepuasan kerja [1], [2], [15]

Pengaruh Supervisi terhadap Kepuasan Kerja

Hasil perhitungan yang telah dikemukakan di atas maka diketahui bahwa supervisi berpengaruh terhadap kepuasan kerja pegawai. Hasil yang didapatkan diperoleh dari perhitungan sig 0,000 lebih kecil dari 0,05 dan nilai thitung lebih besar dari tabel $(5,074>$ 1.98472). Koefisien regresi supervisi memiliki tanda positif yang berarti semakin 
baik supervisi maka semakin baik juga kepuasan kerja pegawai. Hal ini sesuai dengan penelitian sebelumnya yang dilakukan bahwa supervisi berpengaruh secara signifikan dan positif terhadap kepuasan kerja [13], [16].

\section{Pengaruh Lingkungan Kerja terhadap} Kepuasan Kerja

Berdasarkan hasil perhitungan yang telah dikemukakan di atas maka diketahui bahwa lingkungan kerja berpengaruh terhadap kepuasan kerja pegawai. Hasil yang didapatkan diperoleh dari perhitungan sig 0,000 lebih kecil dari 0,05 dan nilai $t_{\text {hitung }}$ lebih besar dari $t_{\text {tabel }}(5,269>1.98472)$. Koefisien regresi lingkungan kerja memiliki tanda positif yang berarti semakin baik lingkungan kerja maka semakin baik juga kepuasan kerja pegawai. Hal ini sesuai dengan penelitian sebelumnya yang dilakukan bahwa lingkungan kerja berpengaruh secara signifikan dan positif terhadap kepuasan kerja [8], [9], [17]

\section{KESIMPULAN}

1. Berdasarkan hasil perhitungan statistik variabel Komunikasi Organisasi memiliki nilai sig lebih kecil dari nilai tabel maka Ho ditolak. Oleh karena itu secara parsial terdapat pengaruh yang signifikan dari komunikasi organisasi terhadap kepuasan kerja pegawai

2. Hasil perhitungan statistic variable supervise memiliki nilai signifikan yang lebih kecil dari nilai tabel maka Ho ditolak. Oleh karena itu dapat disimpulkan bahwa secara parsial terdapat pengaruh signifikan dari Supervisi terhadap Kepuasan Kerja Pegawai.

3. Berdasarkan hasil perhitungan statistik variabel Lingkungan Kerja memiliki nilai sig lebih kecil dari nilaitabel, maka Ho ditolak. secara parsial terdapat pengaruh signifikan dari Lingkungan Kerja terhadap Kepuasan Kerja Pegawai.

4. Berdasarkan hasil perhitungan statistik variabel Komunikasi Organisasi, Supervisi dan Lingkungan Kerja memiliki nilai $\mathrm{F}$ hitung lebih besar dari nilai $\mathrm{F}$ tabel, maka Ho ditolak. secara simultan terdapat pengaruh signifikan dari Komunikasi Organisasi, Supervisi dan Lingkungan Kerja terhadap Kepuasan Kerja Pegawai.

\section{DAFTAR PUSTAKA}

[1] T. Safari, W. Zulkarnaen, and H. Nurhanipah, "Pengaruh Komunikasi Organisasi Terhadap Kepuasan Kerja Karyawan di PD. BPR LPK Garut Kota Cabang Bayongbong," J. Ilm. MEA (Manajemen, Ekon. Akuntansi), vol. 3, no. 2, pp. 134-149, 2019, doi: 10.31955/mea.vol3.iss2.p.

[2] Novieka and A. Prasetya, "Pengaruh Komunikasi Organisasi Terhadap Kepuasan Kerja dan Komitmen Organisasional (Studi pada Karyawan PT PLN Persero Area Pasuruan)," $J$. Adm. Bisnis, vol. 61, no. 4, pp. 133142, 2018.

[3] S. Sofyani, "Pengaruh Supervisi, Kepuasan Kerja, Dan Stress Kerja Terhadap Kinerja Karyawan Jasa Kontruksi,” 2018.

[4] R. Erwin and W. Feriyana, "Kompetensi Profesional, Dan 
Supervisi Pendidikan Serta Disiplin Kerja Dalam Mempengaruhi Kinerja Guru Smp Negeri 1 Bumiagung Waykanan Lampung," J. Aktual, vol. 17, no. 1, p. 53, 2019, doi: 10.47232/aktual.v17i1.33.

[5] M. Oktaliani, "Pengaruh pelatihan dan supervisi terhadap kedisiplinan kerja dan dampaknya pada prestasi kerja pegawai negeri sipil," J. Ilmu Manaj., vol. 7, no. 1, pp. 1-16, 2017.

[6] B. Burhannudin, M. Zainul, and M. Harlie, "Pengaruh Disiplin Kerja, Lingkungan Kerja, dan Komitmen Organisasional terhadap Kinerja Karyawan: Studi pada Rumah Sakit Islam Banjarmasin," J. Maksipreneur Manajemen, Koperasi, dan Entrep., vol. 8, no. 2, p. 191, 2019, doi: 10.30588/jmp.v8i2.425.

[7] D. Daniyaturrizkiyah, "Pengaruh Lingkungan Kerja Terhadap Kinerja Pegawai di Sekretariat Dewan Perwakilan Rakyat Daerah (DPRD) Kabupaten Ciamis Dini Daniyaturrizkiyah ABSTRAK," Din. J. Ilm. Ilmu Adm. Negara, pp. 17-30, 2011.

[8] Q. S. Aruan and M. Fakhri, "Pengaruh Lingkungan Kerja Terhadap Kepuasan Kerja Karyawan Lapangan Departemen Grasberg Power Distribution PT. Freeport Indonesia," Modus, vol. 27, no. 2, pp. 141-162, 2015.

[9] M. Wibowo, M. Al Musadieq, and G. E. Nurtjajono, "PENGARUH LINGKUNGAN KERJA TERHADAP KEPUASAN KERJA KARYAWAN (Studi pada Karyawan PT.Telekomunikasi Indonesia Tbk. Kandatel Malang)," J. Adm. Bisnis, vol. 16, no. 1, p. 84891, 2014.

[10] M. R. Romadona and S. Setiawan, "Communication of Organizations in Organizations Change's Phenomenon in Research and Development Institution," J. Pekommas, vol. 5, no.
1, p. $91, \quad 2020$, doi: 10.30818/jpkm.2020.2050110.

[11] O. M. Katuuk, N. Mewengkang, and E. R. Kalesaran, "Peran Komunikasi Organisasi Dalam Meningkatkan Eksistensi Sanggar Seni Vox Angelica," e-journal "Acta Diurna," vol. V, no. 5, pp. 1-10, 2016.

[12] T. Awaru, N. Fitria, N. Ainun, M. Khairunisha, and Husnia, "Komunikasi Organisasi," Univ. Muslim Indones., no. January, p. 9, 2019.

[13] S. Sarjana, "Effects Of Oganizatonal Supervision And Atmosphere Towards Job Satisfaction," $J$. Kependidikan, vol. 24, no. 2, pp. 173186, 2012.

[14] A. Firdausi, "Pengaruh Supervisi dan Kepercayaan Diri terhadap Kepuasan Kerja Guru SMKN di Jakarta Timur," SAP (Susunan Artik. Pendidikan), vol. 2, no. 3, 2018, doi: 10.30998/sap.v2i3.2453.

[15] M. Seidy, "Pengaruh Komunikasi Dan Kompensasi Terhadap Kepuasan Kerja Karyawan Kantor Radio Republik Indonesia (Rri) Manado," $J$. EMBA J. Ris. Ekon. Manajemen, Bisnis dan Akunt., vol. 6, no. 4, pp. 3458-3467, 2018, doi: 10.35794/emba.v6i4.21612.

[16] E. Oktaviani and A. Marlinah, "Pengaruh Tindakan Supervisi, Motivasi , Profesional, Locus of Control, Konflik Peran Terhadap Kepuasan Kerja," J. Bisnis dan Akunt., vol. 16, no. 1, 2014.

[17] I. W. R. S. Putra and I. G. A. D. Adnyani, "Pengaruh Komunikasi, Budaya Organisasi Dan Lingkungan Kerja Fisik Terhadap Kepuasan Kerja Karyawan Ramada Bintang Bali," EJurnal Manaj. Univ. Udayana, vol. 8, no. 4, p. 2014, 2019, doi: 10.24843/ejmunud.2019.v08.i04.p05. 